\title{
Treatment Outcomes and Associated Risk Factors of Severely Malnourished under Five Children Admitted to Therapeutic Feeding Centers of Mekelle City, Northern Ethiopia
}

\author{
Melaku Gebremichael1, Afework Mulugeta Bezabih2*, Mache Tsadik² \\ ${ }^{1}$ Benishangul Bureau of Health, Assosa, Ethiopia \\ ${ }^{2}$ Mekelle University, Mekelle, Ethiopia \\ Email: afework.mulugeta@gmail.com
}

Received 8 April 2014; revised 18 May 2014; accepted 5 July 2014

Copyright (C) 2014 by authors and OALib.

This work is licensed under the Creative Commons Attribution International License (CC BY). http://creativecommons.org/licenses/by/4.0/

(c) (i) Open Access

\section{Abstract}

Background: Despite presence of clinical management protocols for treating severe acute malnutrition, its case fatality rate remains high in health facilities from developing countries. Objectives: To assess treatment outcomes and associated risk factors for death of children aged 6 - 59 months with complicated severe acute malnutrition. Methods: A cohort of 469 children aged 6 - 59 months with complicated severe acute malnutrition admitted to nutritional rehabilitation units of Mekelle City were followed retrospectively. Data on nutritional status, socio-demographic factors, admission medical conditions and management characteristics were collected. Median test, Chi-square test and Cox's proportional hazard regression were used for statistical analysis. Results: Overall case fatality rate was $\mathbf{1 2 . 8 \%}$. The median length of stay and median weight gain was 17 days and $12.1 \mathrm{~g} / \mathrm{kg} /$ day, respectively. Two third of the deaths occurred during the first week of admission. Diarrhea (HR: 2.45, 95\% CI: 1.23 - 4.89), IV antibiotic (HR: 5.87, 95\% CI: 1.73 - 19.87), blood transfusion (HR: 3.05, 95\% CI: 1.51 - 6.17) and IV infusion (HR: 2.52, 95\% CI: 1.25 - 5.07) were found to be associated with time to death. Conclusion: Unacceptably high case fatality rate was observed at the therapeutic feeding units of Mekelle City. Diarrhea, IV antibiotic, blood transfusion and IV infusion were the risk factors for death of severely malnourished under five children. Appropriate clinical management of severe acute malnutrition in the first week of inpatient stay with frequent monitoring for signs associated with clinical deterioration of children hospitalized with complicated SAM is most critical to the survival of the children.

\section{Keywords}

Severe Acute Malnutrition, Hospitalized Death, Treatment Outcome, Nutritional Rehabilitation Units, Mekelle

\footnotetext{
${ }^{*}$ Corresponding author.
}

How to cite this paper: Gebremichael, M., Bezabih, A.M. and Tsadik, M. (2014) Treatment Outcomes and Associated Risk Factors of Severely Malnourished under Five Children Admitted to Therapeutic Feeding Centers of Mekelle City, Northern Ethiopia. Open Access Library Journal, 1: e446. http://dx.doi.org/10.4236/oalib.1100446 


\section{Introduction}

At least 19 million preschool children are affected by severe acute malnutrition (SAM) globally [1] [2]. Africa is one of the regions with the highest prevalence of SAM in preschool age children [1]. For children with SAM, the risk of death is approximately 10-fold higher compared to normally nourished children [3]. Because of the high risk of death, most severely malnourished children are managed in health facilities including hospitals [4]. In an effort to improve the quality of hospital care for severely malnourished children and reduce case fatality rates, standardized guidelines have been developed by WHO [5] and Ethiopia [6] for SAM patients. When these guidelines are followed, it has been possible to reduce case fatality rate considerably [7] [8]. Despite hospitalization and development of standardized guidelines, recent reviews indicated that the case fatality rates for inpatient treatment of severe acute malnutrition using the WHO protocol ranged from 3.4\% to 35\% [9]. A likely cause of this high inpatient mortality is faulty case management [10]. A survey of 79 treatment centers has shown that practices that could have fatal consequences such as anemia treated with iron at admission were widespread [10]. Inappropriate treatment of dehydration, anemia and diarrhea were reported to cause death in children with SAM [11] [12]. Studies also showed that HIV positive children had a higher risk of death than HIV-negative children [11] [13] [14].

No studies examined the treatment outcomes and potential risk factors of severely malnourished children from Tigray, Northern Ethiopia where there is high prevalence of stunting (51.4\%) [15]. We therefore conducted a retrospective review of records of severely malnourished children from the therapeutic feeding centers (TFCs) of Mekelle City to assess the treatment outcomes, identify the risk factors for mortality and suggest potential interventions to reduce mortality of hospitalized preschool children with complicated SAM.

\section{Methods}

\section{Sampling Sites and Methods}

The study was conducted in the TFCs of Mekelle and Ayder referral hospitals from Mekelle City. Currently, the hospitals provide various services ranging from primary to specialized care and serve urban and rural populations from near and far districts. Admissions to the TFCs of Mekelle and Ayder Hospitals were on average 27 and 128 per year, respectively.

A facility based retrospective analysis of records was conducted on cohort of severely malnourished children admitted to the TFCs of Mekelle City between September 2008 and December 2011. Criteria for inclusion of the 6 - 59 months old children were weight-for-height (WFH) $<70 \%$ or less than minus 3 Z-score of WFH; weight-forlength (WFL) $<70 \%$ or less than minus 3 Z-score of WFL; Mid Upper Arm Circumference (MUAC) $<110 \mathrm{~mm}$ with length $>65 \mathrm{~cm}$ or presence of bilateral pitting edema [6].

Sample size estimation for the comparison of survival curves between two groups (edematous and non-edematous) under the Cox-proportional hazards model was used to calculate the sample size. Accordingly, four hundred sixty nine (469) randomly selected medical records of children aged 6 - 59 months with complicated SAM were included in the study.

\section{Data Collection and Analysis}

A structured data extraction form which had been evaluated by a pediatrician was used to collect data from registration books and patient records. Patients' medical record number was obtained from the registration books so that their record could be easily retrieved from medical record unit. Four nurses who took training on the management of severe acute malnutrition filled in the data extraction form from patient records. They were also trained for half a day on how and what information they would be collecting. A supervisor was assigned to each TFC so that quality of the data was ensured.

The data were entered, cleaned, and coded in SPSS while analysis was carried out using STATA 11. Ten percent of the data were double entered and discrepancies reviewed by an independent third person. Data extraction 
forms were checked prior to data entry and completeness, range and logic checks were carried out regularly to ensure the quality of the data. Any data that was in complete, appear to be out of range or do not comply with the logic checks were checked together with the supervisor.

The 2006 WHO Anthro software version 3.2.2 was used to calculate weight-for-height/length Z-scores. A variable "weight-for-height/length z (WHZ/WLZ) score" was created from the admission weight and admission height. Another variable called "clinical forms of malnutrition" was created based on a combination of children's admission edema, MUAC and WHZ. Accordingly, children were classified as "Marasmic" if they had WHZ less than -3SD or MUAC less than $11 \mathrm{~cm}$ but not edema; "Kwashiorkor" if they had edema but their WHZ was $\geq-3 \mathrm{SD}$ or MUAC $\geq 11 \mathrm{~cm}$, or "Marasmic-Kwashiorkor" if they had both edema and WHZ $<-3 \mathrm{SD}$ or MUAC < $11 \mathrm{~cm}$ [11]. Treatment outcomes of severely malnourished children were calculated and compared with the 2007 protocol for management of SAM in Ethiopia [6]. Bivariate Cox-proportional hazard regression was used to measure association of each baseline characteristics with time to death. Factors that were associated with time to death at 25 percent significance level were included in the multivariate analysis. Stepwise Cox's proportional hazard regression with likelihood ratio test was used to identify important predictor variables. Multiple imputation estimates were obtained for serostatus and hemoglobin. Statistical significance was declared if the p-value is less than 0.05 .

\section{Ethical Consideration}

Ethical clearance was obtained from the ethical review committee of the College of Health Sciences (CHS) of Mekelle University. No information obtained from the medical records was disclosed to any third person. Patient identification variables such as name were not used in the study. This study did not inflict harm on or expose children to unnecessary risk as a result of reviewing their medical records.

\section{Standard and Operational Definitions}

Treatment outcome data was coded as "recovered”, “died”, “defaulted” or "non-responder”. Recovery or nutritional cure was defined as reaching $>80 \%$ of the reference median weight for height. Defaulters were those who were absent for 2 consecutive weighing (2 days). Death referred to the patient that died while he/she was in the program. Non-responder referred to patient that did not reach the discharge criteria after 40 days in the inpatient program. Length of stay referred to number of days that the patient stays in the in-patient program. Weight gain referred to increase in weight of the patient after being admitted in the in-patient program. The following formulas were used in this study [6].

Recovery rate $=$ No of patient discharged for recovery/total No of exits.

Death rate $=$ No of patient died in the program/total No of exits.

Defaulter rate $=$ No of true defaulters/total No of exits.

Non-responder rate $=$ No of non-responder/total No of exits.

Weight gain $=\{$ discharge weight $(\mathrm{g})-$ admission weight $(\mathrm{g})\} /\{$ admission weight $(\mathrm{kg}) \times$ No of days between admission and discharge day .

Average weight gain = sum of weight gains/No of 6 - 59 months cured.

Average length of stay $=$ sum of length of stay/No of 6 - 59 months cured.

Censored referred to those severely malnourished children left the program alive. The event (outcome of interest) was considered to be death of severely malnourished children while in the program.

\section{Results}

Boys accounted $57.4 \%$ of the admitted children. About $67 \%$ of the children were below 24 months. The median age was 18 months. Marasmus accounted for $58.8 \%$ of all admissions of SAM and about $41 \%$ of the children had bilateral pitting edema (Table 1). The mean weight-for-height Z-score for non-edematous severely malnourished children was -4.6 .

The multiple imputation mean estimate of hemoglobin level (Hgb) was $9.7 \mathrm{~g} / \mathrm{dl}$. Half of the children with hemoglobin level measured in the first 48 hours after admission were anaemic ( $\mathrm{Hgb}<10 \mathrm{~g} / \mathrm{dl}$ ), 39 (8.5\%) were severely anemic ( $\mathrm{Hgb}<5 \mathrm{~g} / \mathrm{dl}$ ) and $20(4.4 \%)$ were very severely anemic (Hgb $<4 \mathrm{~g} / \mathrm{dl}$; Table 2).

The main medical complications on admissions were diarrhea (63.4\%), dehydration (30.8\%), intractable 
Table 1. Nutritional edema status by age and sex among severely malnourished children of 6 - 59 months admitted to Mekelle therapeutic feeding centers from September 2008 to December 2011 G.C.

\begin{tabular}{|c|c|c|c|c|c|}
\hline \multirow{2}{*}{ Age category } & \multicolumn{2}{|c|}{ Male } & \multicolumn{2}{|c|}{ Female } & \multirow{2}{*}{ Total } \\
\hline & Edema $^{a}$ & No edema ${ }^{\mathrm{b}}$ & Edema $^{\mathrm{a}}$ & No edemab & \\
\hline 6 - 11.9 months & $17(16 \%)$ & 39 (23.9\%) & $15(17.2 \%)$ & 34 (30.1\%) & $105(22.4 \%)$ \\
\hline 12 - 23.9 months & $51(48.1 \%)$ & 79 (48.5\%) & $38(43.7 \%)$ & 40 (35.4\%) & $208(44.3 \%)$ \\
\hline 24 - 35.9 months & 27 (25.5\%) & $28(17.2 \%)$ & 20 (23\%) & $26(23 \%)$ & $101(21.5 \%)$ \\
\hline 36 - 47.9 months & 7 (6.6\%) & 8 (4.9\%) & $10(11.5 \%)$ & $6(5.3 \%)$ & $31(6.6 \%)$ \\
\hline 48 - 59.9 months & $4(3.8 \%)$ & $9(5.5 \%)$ & $4(4.6 \%)$ & $7(6.2 \%)$ & $24(5.1 \%)$ \\
\hline Total & $106(100 \%)$ & $163(100 \%)$ & 87 (100\%) & $113(100 \%)$ & 469 (100\%) \\
\hline
\end{tabular}

${ }^{\mathrm{a}}$ Bilateral pitting edema with or without a weight-for-height $<-3 \mathrm{SD}$. ${ }^{\mathrm{b}}$ Weight-for-height $<-3 \mathrm{SD}$ or MUAC $<11 \mathrm{~cm}$, no bilateral pitting edema.

Table 2. Distribution of hemoglobin levels of 469 children aged 6 - 59 months with severe malnutrition admitted to therapeutic feeding centers of Mekelle City September 2008-December 2011 G.C.

\begin{tabular}{cccc}
\hline Hemoglobin level $(\mathrm{g} / \mathrm{dl})$ & Frequency & Percentage (\%) & $95 \%$ CI \\
\hline$<4$ & 20 & 4.4 & $1.6-7.2$ \\
$4-4.9$ & 19 & 4.1 & $1.2-7.1$ \\
$5-8$ & 96 & 20.4 & $15.9-24.8$ \\
$8.1-10$ & 112 & 23.8 & $18.9-28.6$ \\
$>10$ & 222 & 47.4 & $41.5-53.2$ \\
Total & 469 & 100.0 & \\
\hline
\end{tabular}

vomiting (57\%), acute gastroenteritis (13.4\%), pneumonia (19.5\%) and any form of tuberculosis (7.3\%). HIV prevalence based on KHB HIV-1/2 tests and DNA PCR test for children less than 18 months was $11.3 \%$. Two children of age less than 18 months were reactive for rapid HIV tests but not confirmed by DNA PCR.

The overall case fatality rate of the TFCs was $12.8 \%$. The median length of stay and median weight gain were 17 days and $12.1 \mathrm{~g} / \mathrm{kg} /$ day, respectively (Table 3). No significant difference in median weight gain and median length of stay was observed by serostatus at p-value $=0.192$ and p-value $=0.07$, respectively.

The total time at risk for the cohort of severely malnourished children admitted to the TFCs of Mekelle City was 8274 days and the median time at risk was 15 days. The total number of failures (deaths) was 60, two third of the deaths occurring in the first week of admission. About 28\% (17/60) died within 48 hours of admission. The overall incidence of death was 7.3 per 1000 person-days. The probability of surviving of 56 days or more for severely malnourished children was 0.78 (Figure 1).

In the bivariate analysis of selected baseline and management characteristics, blood transfusion, intravenous fluid infusion, TFC, intravenous antibiotic administration, clinical forms of malnutrition, edema status, nasogastric tube feeding and diarrhea were all associated with time to death at 25 percent significant level (Table 4). There was no significant difference in time to death by sex, dehydration status, serostatus and age (below 24 months or not) at 25 percent significant level.

Factors that were associated with time to death at 25 percent significant level in the bivariate analysis were included in the final multivariate analysis. But diarrhea, blood transfusion, intravenous fluid infusion and intravenous antibiotic administration were found to be statistically significant at 5 percent (Table 5).

The adjusted relative risk of fatality comparing infused and not-infused groups was 2.52 (95\% CI 1.25 - 5.07). Likewise, the adjusted relative risk of the fatality for diarrhea, intravenous antibiotic administration and blood transfusion were 2.45 (95\% CI 1.23 - 4.89), 5.87 (95\% CI 1.73 - 19.87), and 3.05 (95\% CI 1.51 - 6.17), respectively.

\section{Discussion}

The case fatality rate (12.8\%) was unacceptably high when compared to the SPHERE standards that recommend less than $10 \%$ of death [16]. The median length of stay (17 days) and median weight gain $(12.1 \mathrm{~g} / \mathrm{kg} / \mathrm{day})$ of the cohort of severely malnourished children fall within the acceptable range recommended by SPHERE for inpatient management. The SPHERE standard recommends weight gain of greater than or equal to $8 \mathrm{~g} / \mathrm{kg} / \mathrm{day}$ and 
Table 3. Performance indicator values of inpatient therapeutic feeding centers of Mekelle City as compared to the SPHERE project reference values.

\begin{tabular}{ccccc}
\hline \multirow{2}{*}{ Performance indicators } & Mekelle hospital & Ayder referral hospital & \multicolumn{2}{c}{ The SPHERE project reference values ${ }^{16}$} \\
\cline { 3 - 4 } & $69.4 \%$ & $69.8 \%$ & Acceptable & Alarming \\
\hline Recovery rate & $17.6 \%$ & $11.7 \%$ & $>75 \%$ & $<50 \%$ \\
Death rate & $9.4 \%$ & $12.2 \%$ & $<10 \%$ & $>15 \%$ \\
Defaulter rate & $17.4 \mathrm{~g} / \mathrm{kg} / \mathrm{day}$ & $10.7 \mathrm{~g} / \mathrm{kg} /$ day & $\geq 8 \mathrm{~g} / \mathrm{kg} / \mathrm{day}$ & $<8 \mathrm{~g} / \mathrm{kg} / \mathrm{day}$ \\
Weight gain & 16 days & 17 days & $<28$ days & $>42$ days \\
Length of stay & & & & \\
\hline
\end{tabular}

Table 4. Bivariate analysis of factors associated with time to death.

\begin{tabular}{|c|c|c|c|}
\hline Co-variates & Unadjusted hazard ratio & $95 \% \mathrm{CI}$ & p-value \\
\hline $\begin{array}{l}\text { Age group } \\
\leq 24 \text { months } \\
>24 \text { months }\end{array}$ & $\begin{array}{c}1 \\
1.0\end{array}$ & $0.5-1.9$ & 0.99 \\
\hline $\begin{array}{l}\text { Edema } \\
\text { Absent } \\
\text { Present }\end{array}$ & $\begin{array}{c}1 \\
1.4\end{array}$ & $0.8-2.4$ & 0.19 \\
\hline $\begin{array}{l}\text { Serostatus } \\
\text { Negative } \\
\text { Positive }\end{array}$ & $\begin{array}{c}1 \\
1.38\end{array}$ & $0.5-3.5$ & 0.63 \\
\hline $\begin{array}{l}\text { Sex } \\
\text { Female } \\
\text { Male }\end{array}$ & $\begin{array}{c}1 \\
0.9\end{array}$ & $0.5-1.5$ & 0.74 \\
\hline $\begin{array}{c}\text { Clinical forms of malnutrition } \\
\text { Marasmus } \\
\text { Kwashiorkor } \\
\text { Marasmic-kwashiorkor }\end{array}$ & $\begin{array}{c}1 \\
1.0 \\
1.8\end{array}$ & $\begin{array}{l}0.5-2.1 \\
1.0-3.2\end{array}$ & $\begin{array}{l}0.98 \\
0.05\end{array}$ \\
\hline $\begin{array}{c}\text { Axilliary temperature }<35.5^{\circ} \mathrm{C} \\
\text { No } \\
\text { Yes }\end{array}$ & $\begin{array}{c}1 \\
0.9\end{array}$ & $0.3-2.9$ & 0.87 \\
\hline $\begin{array}{c}\text { Blood transfused } \\
\text { No } \\
\text { Yes }\end{array}$ & $\begin{array}{c}1 \\
3.6\end{array}$ & $1.9-7.0$ & $<0.001$ \\
\hline $\begin{array}{l}\text { Diarrhea } \\
\text { Absent } \\
\text { Present }\end{array}$ & $\begin{array}{c}1 \\
2.4\end{array}$ & $1.2-4.6$ & \\
\hline $\begin{array}{c}\text { Intravenous fluid infused } \\
\text { No } \\
\text { Yes }\end{array}$ & $\begin{array}{c}1 \\
4.8\end{array}$ & $2.7-8.6$ & $<0.001$ \\
\hline $\begin{array}{l}\text { Dehydration } \\
\text { No } \\
\text { Yes }\end{array}$ & $\begin{array}{c}1 \\
1.2\end{array}$ & $0.67-2.15$ & 0.49 \\
\hline $\begin{array}{c}\text { Therapeutic feeding center } \\
\text { Mekelle } \\
\text { Ayder }\end{array}$ & $\begin{array}{c}1 \\
0.6\end{array}$ & $0.3-1.0$ & $<0.001$ \\
\hline $\begin{array}{c}\text { NG tube feeding } \\
\text { No } \\
\text { Yes }\end{array}$ & $\begin{array}{c}1 \\
2.4\end{array}$ & $1.2-4.7$ & 0.014 \\
\hline $\begin{array}{c}\text { Intravenous antibiotic } \\
\text { No } \\
\text { Yes }\end{array}$ & $\begin{array}{c}1 \\
10.6\end{array}$ & $3.3-33.9$ & $<0.001$ \\
\hline
\end{tabular}




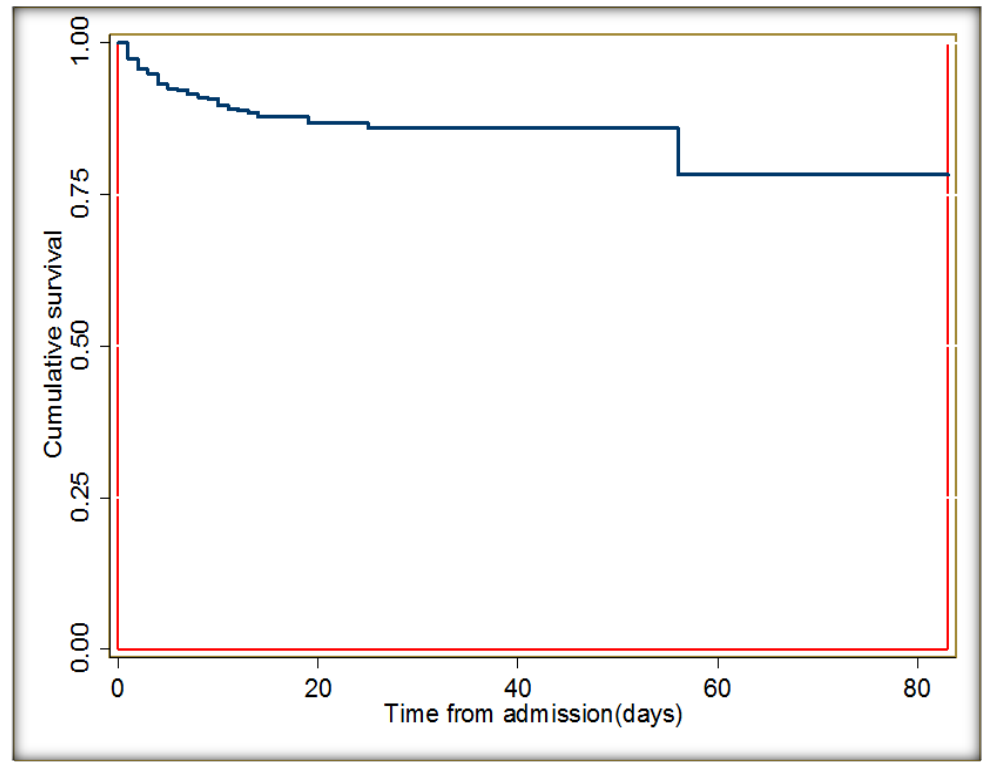

Figure 1. Kaplan-Meier survival estimates for severely malnourished children admitted to therapeutic feeding centers of Mekelle City September, 2008December 2011 G.C.

Table 5. Multivariate analysis of factors associated with time to death.

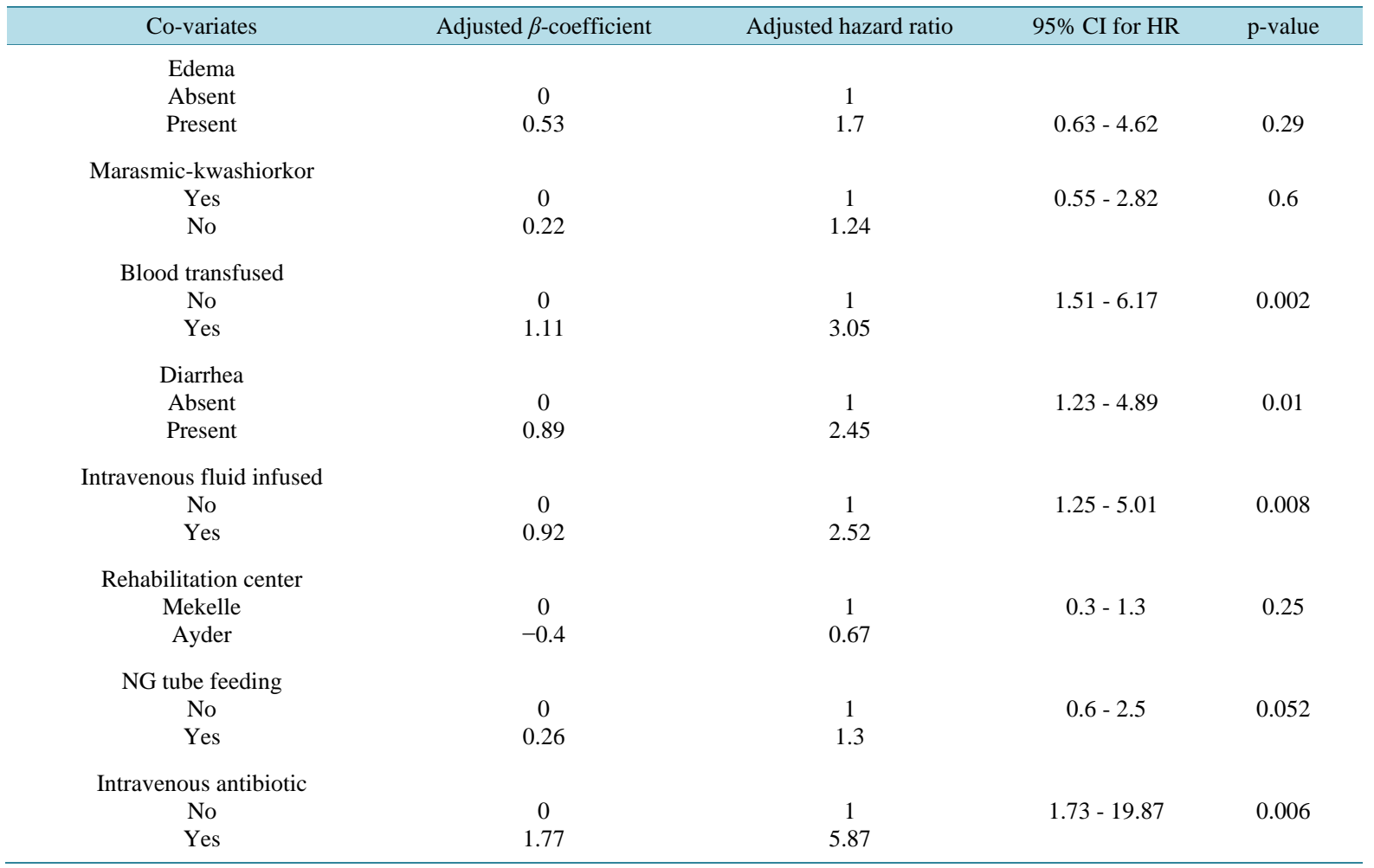

length of stay of less than 28 days [16]. However, the length of stay observed in this study (17 days) was more than the length of stay of 10 days reported from Zambia [11] and lower than the length of stay (21 - 25 days) reported from Southern Ethiopia [8]. The median weight gain in this study was higher than the weight gain of 10 $\mathrm{g} / \mathrm{kg} /$ day from Burkina Faso [17] and lower than the average weight gain of 13.4 to $14 \mathrm{~g} / \mathrm{kg} / \mathrm{day}$ for children 
with SAM from Southern Ethiopia [8].

The predominant (58.8\%) form of malnutrition was marasmus. Despite the comparability of the ages of children, the study conducted in Zambia reported low prevalence (25\%) of marasmus [11]. This could be due to the difference in causes of malnutrition across various settings. The prevalence of HIV/AIDS among severely malnourished children in this study was $11.3 \%$ and similar findings were reported from South West Ethiopia with a prevalence of $13.8 \%$ [18]. But it was found to be lower when compared to studies done in Malawi, 21.6\% [19], Zambia, 30\% [11], Uganda, 38.6\% [12] and recent systematic review and meta-analysis, 29.2\% [13]. This could be due to the general decreasing trend in the prevalence of HIV/AIDS in Ethiopia. Similar to other prospective cohort studies elsewhere [12] [18], we found that HIV status didn't significantly increase the case fatality rate in hospitalized children with complicated SAM. Faulty case management might have overshadowed the effect of HIV/AIDS on mortality among the severely malnourished children.

Higher case fatality rate was observed in our study. In agreement with our findings, high case fatality rates from Mulago referral and teaching hospital, Uganda, 24\% [12], urban TFCs from Burkina Faso, 16\% [17], Zambia university teaching hospital, Zambia, 30\% [11], Gonder University teaching hospital, Ethiopia, 18\% [20] and 13.7\% from Yirgalem hospital of Southern Ethiopia, 14\% [8] were reported. On the other hand, a study conducted in Southern Nations, Nationalities, and People's Region of Ethiopia showed minimum case fatality rate (3.6\%) signifying that remarkable reduction of CFR can be achieved with the current Ethiopian National Guideline for Management of SAM [6].

Patients in this study were at risk of early death, as $28 \%$ of the deaths occurred in the first 48 hours of admission. Early deaths were probably due to the very wasted and critical condition of those children on admission, leading to failure of any treatment. Similarly, early death was also reported in $29 \%$ and $30.6 \%$ of children from studies conducted in Uganda [12] and Zambia [11], respectively. Diarrhea and management characteristics (IV infusion, IV antibiotic, and blood transfusion) were associated with time to death. Presence of association between management characteristics and time to death could be related to inappropriate management of severe malnutrition. Schofield and Ashworth reported that faulty case-management contributes for high case fatality rate [10]. A recent prospective audit done in Kenya also showed that quality of care for children admitted with SAM at Kenyatta National referral hospital was inadequate and often didn't follow the WHO guidelines [21]. In this prospective study, only one child out of twelve who were transfused had correct volume of blood and five had hemoglobin value more than $5 \mathrm{gm} / \mathrm{dl}$. Intravenous fluids were given against the guidelines. Moreover, monitoring for over-hydration was not done and neither were volumes of fluids given properly recorded. Consequently a case fatality rate of 38\% was observed in the hospital [21] signifying the need for the administration of transfusion and infusion in accordance with the treatment guidelines and with close monitoring.

In the hospitalized children with SAM, diarrhea was found to be a frequent complication resulting in adverse outcomes. Children with SAM complicated by diarrhea had a higher risk of death than those who did not have diarrhea during their hospital stay (HR: 2.45, 95\% CI: 1.23 - 4.89). Similar findings were reported from Kenya where diarrhea was a common complication (49\%) resulting in higher mortality in children hospitalized with severe acute malnutrition [22] and children with severe malnutrition are more prone to infections than others due to the immunosuppressive effect of malnutrition and the loss of the protective mucosal barrier in the gastrointestinal tract [23]. Moreover, studies have shown that severely malnourished children are more prone to gut barrier dysfunction [24], Escherichia coli bacteraemia [25] and higher mortality from invasive bacterial infection [26].

The Ethiopian National Guideline for Management of Severe Acute Malnutrition recommends withholding blood transfusion unless hemoglobin level is less than $4 \mathrm{gm} / \mathrm{dl}$ [6]. On the other hand, Banchou and his colleagues reported that transfusion may be indicated if hemoglobin level is less than $5 \mathrm{gm} / \mathrm{dl}$ [12]. In this study, six children with hemoglobin level greater than $5 \mathrm{mg} / \mathrm{dl}$ were transfused, suggestive of poor management practices in the TFCs in the two hospitals from Mekelle City.

The strength of this study was that it utilized data originated from real life scenario. Hence, it would give the insight of what really was going on in the TFCs of Mekelle City. However, the study has limitations as well. Retrospective nature of the study possibly introduces bias as the quality of information obtained from these finding is highly dependent on the completeness of patient records. Weight gains in edematous SAM patients were not calculated because the weight at resolution of edema was not available. In addition, bias from the data collectors and bias due to survivors were some of the limitations of this study.

In conclusion, diarrhea was highly prevalent and had significant effect on the outcome of children with severe acute malnutrition. This calls for strengthened community-level interventions, targeted towards prevention and 
treatment of diarrhea. Simple and effective intervention such as zinc supplementation, oral rehydration solutions and, water and sanitation interventions at the community level deserve a critical look. Other risk factors for increased case fatality were intravenous fluid infusion, intravenous antibiotics, and blood transfusion. Any intervention to reduce deaths need to focus on guideline compliance with respect to intravenous fluid infusion, intravenous antibiotics and blood transfusion. This requires continuous training of care providers in the pediatric wards on the management of severe acute malnutrition, especially where staff turnover is common. The first week of inpatient stay with frequent monitoring for signs associated with clinical deterioration of children hospitalized with complicated SAM is most critical to the survival of the children. Hence, prompt and appropriate management especially on co-infections should be given priority to reduce the case fatality rate in TFCs.

\section{Competing Interests}

The authors declare that they have no competing interests.

\section{Authors' Contributions}

MGM, the principal investigator, was involved in the conceptualization and design of the study, data collection, interpretation of the data and drafted the manuscript with substantial input from AM. AM, the corresponding author, was involved in the design, supervision, analysis and interpretation of data and review of the manuscript. MT contributed throughout the design, supervision, interpretation and manuscript preparation.

\section{Acknowledgements}

The authors would like to acknowledge Mekelle University for financial support and Dr Efrem Lemma, a Pediatrician at Ayder Referral Hospital, Mr. Misganaw Daniel and Mr. Bedirudin Shafie for their contribution in the development of data extraction tool and all rounded support.

\section{References}

[1] WHO (2013) Guideline Update: Technical Aspects of the Management of Severe Acute Malnutrition in Infants and Children. World Health Organization, Geneva.

[2] (2012) Levels and Trends in Child Malnutrition: UNICEF-WHO_-The World Bank Joint Child Malnutrition Estimates. Bank U-W-TW, Washington DC.

[3] Black, R.E., Allen, L.H., Bhutta, Z.A., Caulfield, L.E., de Onis, M., Ezzati, M., Mathers, C. and Rivera, J. (2008) Maternal and Child Undernutrition: Global and Regional Exposures and Health Consequences. Lancet, 371, $243-260$. http://dx.doi.org/10.1016/S0140-6736(07)61690-0

[4] WHO (2004) Serious Childhood Problems in Countries with Limited Resources: Background Book on Management of the Child with a Serious Infection or Severe Malnutrition. World Health Organization, Geneva.

[5] WHO (1999) Management of Severe Malnutrition: A Manual for Physicians and Other Health Workers. World Health Organization, Geneva.

[6] FMoH (2007) Protocol for the Management of Severe Acute Malnutrition. Ethiopia-Federal Ministry of Health, Addis Ababa.

[7] Ashworth, A., Chopra, M., McCoy, D., Sanders, D., Jackson, D., Karaolis, N., et al. (2004) WHO Guidelines for Management of Severe Malnutrition in Rural South African Hospitals: Effect on Case Fatality and the Influence of Operational Factors. Lancet, 363, 1110-1115. http://dx.doi.org/10.1016/S0140-6736(04)15894-7

[8] Teferi, E., Lera, M., Sita, S., Bogale, Z., Datiko, D.G. and Yassin, M.A. (2010) Treatment Outcome of Children with Severe Acute Malnutrition Admitted to Therapeutic Feeding Centers in Southern Region of Ethiopia. Ethiopian Journal of Health Development, 24, 234-238.

[9] Lenters, L.M., Wazny, K., Webb, P., Ahmed, T. and Bhutta, Z.A. (2013) Treatment of Severe and Moderate Acute Malnutrition in Low- and Middle-Income Settings: A Systematic Review, Meta-Analysis and Delphi Process. BMC Public Health, 13, S23. http://dx.doi.org/10.1186/1471-2458-13-S3-S23

[10] Schofield, C. and Ashworth, A. (1996) Why Have Mortality Rates for Severe Malnutrition Remained So High? Bulletin of the World Health Organization, 72, 223-229.

[11] Irena, A., Mwambazi, M. and Mulenga, V. (2011) Diarrhea Is a Major Killer of Children with Severe Acute Malnutrition Admitted to Inpatient Set-Up in Lusaka, Zambia. Nutrition Journal, 10, 110. 
[12] Bachou, H., Tumwine, J.K., Mwadine, R.K. and Tylleskar, T. (2006) Risk Factors in Hospital Deaths in Severely Malnourished Children in Kampala, Uganda. BMC Pediatrics, 6, 7. http://dx.doi.org/10.1186/1471-2431-6-7

[13] Fergusson, P. and Tomkins, A. (2009) HIV Prevalence and Mortality among Children Undergoing Treatment for Severe Acute Malnutrition in Sub-Saharan Africa: A Systematic Review and Meta-Analysis. Transactions of the Royal Society of Tropical Medicine and Hygiene, 103, 541-548. http://dx.doi.org/10.1016/j.trstmh.2008.10.029

[14] Chinkhumba, J., Tomkins, A., Banda, T., Mkangama, C. and Fergusson, P. (2008) The Impact of HIV on Mortality during Inpatient Rehabilitation of Severely Malnourished Children in Malawi. Royal Society of Tropical Medicine and Hygiene, 102, 639-644.

[15] CSA (2011) Ethiopia Demographic and Health Survey 2011. Central Statistical Agency (CSA), Addis Ababa.

[16] (2004) Humanitarian Charter and Minimum Standards in Disaster Response. The Sphere Project, Geneva.

[17] Savadogo, L., Zoetaba, I., Donnen, P., Hennart, P., Sondo, B. and Dramaix, M. (2007) Management of Severe Acute Malnutrition. Urban Nutritional Rehabilitation Center, Burkina Faso.

[18] Zelalem, T., Tsinuel, G. and Ayalew, T. (2010) Treatment Outcome of Severe Acute Malnutrition in Children with and without HIV Infection: A Historical Cohort Study in South-West Ethiopia. Ethiopian Journal of Pediatrics and Child Health, 6, 14-26.

[19] Thurstans, S., Kerac, M., Maleta, K., Banda, T. and Nessbit, A. (2008) HIV Prevalence in Severely Malnourished Children Admitted to Nutritional Rehabilitation Centers in Malawi: Geographical and Seasonal Variations a CrossSectional Study. BMC Pediatrics, 8, 22. http://dx.doi.org/10.1186/1471-2431-8-22

[20] Amsalu, S. and Asnakew, G. (2006) The Outcome of Severe Malnutrition in Northwest Ethiopia: Retrospective Analysis of Admissions. Ethiopian Medical Journal, 44, 151-157.

[21] Nzioki, C., Irimu, G., Musoke, R. and English, M. (2009) Audit of Care for Children Aged 6 - 59 Months Admitted with Severe Acute Malnutrition at Kenyatta National Hospital, Kenya. International Health, 1, 91-96.

[22] Talbert, A., Thuo, N., Karisa, J., Chesaro, C., Ohuma, E., Ignas, J., Berkley, J.A., Toromo, C., Atkinson, S. and Maitland, K. (2012) Diarrhea Complicating Severe Acute Malnutrition in Kenyan Children: A Prospective Descriptive Study of Risk Factors and Outcome. PLoS ONE, 7, Article ID: e38321. http://dx.doi.org/10.1371/journal.pone.0038321

[23] Brewster, D.R., Manary, M.J., Menzies, I.S., O’Loughlin, E.V. and Henry, R.L. (1997) Intestinal Permeability in Kwashiorkor. Archives of Disease in Childhood, 76, 236-241. http://dx.doi.org/10.1136/adc.76.3.236

[24] WHO (1999) Management of Severe Malnutrition: A Manual for Physicians and Other Senior Health Workers. World Health Organization, Geneva.

[25] Berkley, J.A., Lowe, B.S., Mwangi, I., Williams, T., Bauni, E., et al. (2005) Bacteremia among Children Admitted to a Rural Hospital in Kenya. The New England Journal of Medicine, 352, 39-47. http://dx.doi.org/10.1056/NEJMoa040275

[26] Brewster, D.R. (2006) Critical Appraisal of the Management of Severe Malnutrition: 3. Complications. Journal of Paediatrics and Child Health, 42, 583-593. http://dx.doi.org/10.1111/j.1440-1754.2006.00933.x 